\title{
Superior mesenteric artery ischemia: endovascular approach
}

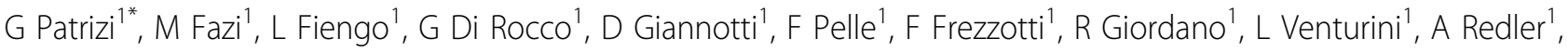 \\ FM Salvatori ${ }^{2}$
}

From XXIII Annual Meeting of the Italian Society of Geriatric Surgery

Lecce, Italy. 2-4 December 2010

\section{Background}

Mesenteric chronic ischemia is an unfrequent pathology usually related to obstructive and stenosing atherosclerotic pathologies of one or more digestive arteries. Among these, the most frequently envolved and revascularised is the superior mesenteric artery. There is a relative prevalence among the female elderly.

Symptoms are often represented by the typical angina abdominis and weight loss. Diarrhea can occur and, without appropriate treatment, this condition can evolve into intestinal infarction.

Treatment can be carried out with traditional surgery or a more recent endovascular approach.

\section{Materials and methods}

We present the case of a 65-year-old patient who was on dialytic treatment for chronic renal failure, and in the past 18 months he was undergoing peritoneal dialysis. The latest sessions had to be interrupted because of the onset of peritonitic symptoms. In the patient's personal history, besides hypertension and dislipidemia, he referred total parathyroidectomy for secondary hyperparathyroidism.

In the last month, he was complaining of the onset of abdominal pain in the right iliac fossa after meals, with homolateral lumbar irradiation, and, more recently during dialysis, which had to be interrupted immediately.

Plain abdominal radiograms showed diffuse calcification of the aorta and its branches, especially in lateral projection, where remarkable calcifications of the celiac trunk and SMA were evident.
Ultrasonography and Doppler demonstrated a preocclusive stenosis at the origin of the SMA and angioMRI confirmed these findings.

Because of the poor general clinical conditions of the patient and to preserve the abdomen for a potential renal transplantation, the endovascular approach was considered the best option. A metallic self-expandable vascular (Wallstent) stent of $7 \mathrm{~mm} \times 3 \mathrm{~cm}$ was placed with a successful outcome.

\section{Results}

Postoperative course was uneventful with complete regression of symptoms and follow-up controls at 3, 6, 12 and 24 months showed no restenosis. The patient after this period is still asymptomatic.

\section{Conclusions}

Endovascular treatment is an effective therapeutic alternative to surgery for the treatment of chronic mesenteric ischemia.

\section{Author details}

'Dipartimento di Scienze Chirurgiche, Policlinico Umberto I, Università di Roma"La Sapienza", Rome, Italy. 'Dipartimento di Scienze Radiologiche, Policlinico Umberto I, Università di Roma"La Sapienza", Rome, Italy.

Published: 24 August 2011

doi:10.1186/1471-2318-11-S1-A43

Cite this article as: Patrizi et al: Superior mesenteric artery ischemia: endovascular approach. BMC Geriatrics 2011 11(Suppl 1):A43.

\footnotetext{
* Correspondence: g_patrizi@yahoo.com

'Dipartimento di Scienze Chirurgiche, Policlinico Umberto I, Università di Roma"La Sapienza", Rome, Italy

Full list of author information is available at the end of the article
}

(c) 2011 Patrizi et al; licensee BioMed Central Ltd. This is an open access article distributed under the terms of the Creative Commons 